\title{
Attitudes and Perceived Barriers among Medical Students towards Clinical Research: A Cross-Sectional Study in an Egyptian Medical School
}

\author{
Abdelrahman Ibrahim Abushouk, ${ }^{1,2}$ Abdelrahman Nazmy Hatata, ${ }^{1}$ \\ Ibrahim Mahmoud Omran, ${ }^{1}$ Mohammed Mahmoud Youniss, ${ }^{1}$ Khaled Fayez Elmansy, \\ and Abdullah Gad Meawad ${ }^{1}$ \\ ${ }^{1}$ Faculty of Medicine, Ain Shams University, Cairo, Egypt \\ ${ }^{2}$ NovaMed Medical Research Association, Cairo, Egypt \\ Correspondence should be addressed to Abdelrahman Ibrahim Abushouk; abdelrahman.abushouk@med.asu.edu.eg
}

Received 3 July 2016; Accepted 14 September 2016

Academic Editor: James J. Brokaw

Copyright (C) 2016 Abdelrahman Ibrahim Abushouk et al. This is an open access article distributed under the Creative Commons Attribution License, which permits unrestricted use, distribution, and reproduction in any medium, provided the original work is properly cited.

\begin{abstract}
Background. Despite the key role played by physician-investigators in bridging basic and clinical sciences, their number has declined significantly in the last decades especially in developing countries. Thus, we aimed to investigate attitudes and perceived barriers towards participation in clinical research among medical students in an Egyptian medical school. Methods. We employed a crosssectional design, in which 420 students from the Faculty of Medicine, Ain Shams University completed a self-administrated questionnaire to assess their attitudes, perceived barriers, and knowledge about clinical research. The results were analyzed considering the students' gender, year of enrollment, and high school background. Results. Seventy medical students from each year of enrollment participated in the study. The majority of students (74.2\%) agree that undergraduates should participate in clinical research. However, only $23.8 \%$ reported engagement in related activities. Students showed low knowledge scores of $1.9 \pm 0.3$ on a scale of six questions. They highlighted several barriers against research participation including lack of time, proper mentoring, and funding. Conclusion. Although the majority of students showed positive attitudes towards clinical research, they reported low participation in related activities, associated with low knowledge scores. Several barriers should be addressed as lack of time, funding, and proper mentoring.
\end{abstract}

\section{Background}

Physician-investigators serve as the link between basic and clinical sciences by discovering the molecular basis of the disease and transforming it into therapeutic interventions [1-3]. Despite their importance, their number has been in a documented decline since the early 1990s [4]. Considering this view, undergraduate clinical research participation is currently more important than before [3]. However, medical education still lacks a consistent structure to increase student participation in clinical research [5]. Early exposure of medical students to clinical research activities fosters their intentions to join an academic medical career $[6,7]$. Even if medical students do not choose to practice clinical research, research knowledge will improve their ability to make evidence based decisions in clinical practice [8-10]. A systematic review of the literature by Straus et al. showed that having a medical school publication positively influences academic career choice among medical students [11]. For these benefits, different approaches have been used to increase student participation in clinical research activities as mandating conductance of research projects in medical schools, establishing indexed student journals, and organizing conferences and training sessions dedicated to student research [12].

Several studies have identified factors such as academic success, gender, intending to join a competitive specialty, and financial worries as key players in defining the probability of students' engagement in clinical research activities [12-15]. 
Moreover, studies have indicated that students in developing countries face more obstacles in conducting research projects than their peers in developed countries including high student teacher ratio and deficient information technology in their teaching hospitals $[16,17]$.

Considering the demands of these countries to increase undergraduate clinical research engagement, it is essential to assess the students' research experience in medical school. The current literature is deficient on the current status of undergraduate clinical research, especially in developing countries, like Egypt [5]. Thus, the objective of this study is to investigate attitudes towards, knowledge about, and perceived barriers against participation in clinical research among Egyptian medical students at Faculty of Medicine, Ain Shams University. We also investigated the effect of several variables including gender, year of enrollment, and high school background on the general attitudes, perception, and engagement in clinical research activities.

\section{Methods}

We followed the STROBE (Strengthening the Reporting of Observational Studies in Epidemiology Statements) guidelines during reporting this cross-sectional study [18].

2.1. Design and Participants. We employed a cross-sectional design in which the target population was all medical students enrolled at Faculty of Medicine, Ain Shams University at September 2015. No exclusion criteria were assigned. The educational model at most Egyptian medical schools is similar where students study basic medical sciences during the first three preclinical years and clinical sciences during the final three years. Medical students at the Faculty of Medicine, Ain Shams University obtain a mandatory clinical research course during the 4th year of enrollment, in which they study biostatistics, scientific writing, and searching for and appraising the evidence. Based on data obtained from the students' affairs office at Faculty of Medicine, Ain Shams University and calculation of a representative sample size by Epi-info software (version 6.04), a sample of 70 medical students was obtained from each year of enrollment by convenience sampling.

2.2. Study Questionnaire. We performed a comprehensive database search for biomedical education articles to generate ideas for the questionnaire items [12, 19, 20]. All retrieved ideas were formulated into questions to assess the target variables. The questionnaire was divided into four sections including the following.

2.2.1. Basic Data about Study Participants. We identified three factors (gender, year of enrollment, and secondary school background) that may influence the students' perception and practice of clinical research, as prespecified in the literature [5]. Both genders and all years of enrollment were adequately represented in this study. There are three types of secondary schools in Egypt (public, private, and international) which qualify for joining the Faculty of Medicine. International schools' students usually study a scientific research introductory course during secondary school and this variable may impact their knowledge and attitudes towards clinical research. To assess their effect, if any, analysis of attitudes and knowledge scores was conducted considering the three variables.

\subsubsection{Attitudes towards Clinical Research}

(1) Item Generation. To conduct a psychometric evaluation of the students' attitudes towards clinical research, we created brainstorming sessions with medical students from different years of enrollment (2nd, 4th, and 6th) and clinical research experts from the Department of Public Health at Faculty of Medicine, Ain Shams University. We also reviewed the literature to generate ideas about assessing the students' attitudes towards clinical research. We used a three-item Likert-type scale (agree, undecided, and disagree) as it is easy to construct and interpret. The questions aimed to assess the students' attitudes towards clinical research, the influence of these attitudes on the students' existing level of participation in related activities, and the desire to conduct clinical research in the future.

(2) Item Validation and Reliability Analysis. We collected 20 positive and 20 negative statements from brainstorming sessions. Six graduate students from Public Health Department were asked to select the most relevant statements, and the items chosen by four of them were included in the attitudes' questionnaire. We also performed an itemtotal correlation analysis in which the total of all items for every student in the highest and lowest score group of the pilot sample (10 students each) was calculated and the items were eliminated if the difference between the highest and lowest groups was not significant at 0.05 level. The attitudes' questionnaire was tested in a cross-sectional pilot study on 40 medical students, chosen by random sampling, that were not included in the final analysis. The pilot sample included 17 males and 23 females, five to seven students for each year of enrollment. Statistical analysis of our pilot sample showed favorable attitudes of enrolled medical students towards clinical research. For example, $92.5 \%$ of students (37/40) agreed that clinical research skills can significantly improve the physicians' clinical practice.

\subsubsection{Knowledge about Clinical Research}

(1) Item Generation. To evaluate the students' knowledge about clinical research, we selected simple multiple choice questions, based on the mandatory clinical research course taught by the Department of Public Health at the fourth year of Faculty of Medicine, Ain Shams University. We had an initial count of 20 questions from which six were chosen during data collection for our pilot study, based on the comprehensibility of the questions and the time needed to answer every one. We also wanted to assess the students' knowledge in different aspects of clinical research such as statistical principles, data collection, and writing and appraising a scientific paper. Although the total number of knowledge assessment items may be considered insufficient, but our major goal was 
not quantitative assessment of the students' knowledge about clinical research, but the formulation of a basic hypothesis about the students' clinical research knowledge that can be verified in future studies. Also we concluded, through the same cross-sectional pilot study, that a longer knowledge assessment questionnaire would be uncomfortable for the enrolled students.

(2) Item Validation. To insure the content validity of the questions, each question was peer-reviewed by two independent experts. The reliability of our knowledge questionnaire was 0.58 according to the Kuder-Richardson formula [21]; that is, we summed up the correct answers of every student in the 40 students' pilot sample and compared them to the score that can be obtained through guessing ( $20 \%$ or 1.2 out of 6 ). Therefore, a score of $1.2 / 6$ or less was attributed to chance, without reflecting a true knowledge of the participant.

\subsubsection{Barriers towards Participation in Clinical Research}

(1) Item Generation. Ten items were primarily synthesized based on literature review of former studies $[5,12,19]$ that investigated the attitudes of medical students towards science and scientific research generally. Also, a pilot sample of 40 medical students was asked to list ten barriers that limit their participation in clinical research activities. We had 10 final items from which three items were removed due to poor discrimination and redundancy. The final respondents were asked to select all possible barriers against participation in clinical research from the available list. The final questionnaire assessed the possible influence of seven barriers on the students' engagement in clinical research activities as lack of mentoring, funding, time, facilities, database inaccessibility, or poor research knowledge and interest.

(2) Item Validation. The selected items were reviewed by a panel of public health and psychology experts and the feedbacks of medical students in the pilot sample were considered regarding the phrasing and comprehensibility of the included items. For further validation of our instrument, we matched our questionnaire to the validation requirements of the COSMIN checklist (consensus based standards for the selection of health measurement instrument) [22].

2.3. Data Collection. Data were collected using a validated, anonymous, self-administrated questionnaire, delivered in a written form to our study participants, after explaining the voluntary nature of the questionnaire and obtaining a verbal consent from the study participants. A pilot study on 40 students was conducted to test the final modified form regarding time of completion, participant comprehension, and the validity of the questions in ascertaining the intended objectives. The confidentiality of obtained data was maintained according to the Helsinki Declaration of bioethics.

2.4. Data Analysis. Statistical analysis was performed using SPSS version 20 (Statistical Package for Social Sciences) with a $p$ value less than 0.05 being considered statistically significant. Questionnaire forms with more than two missing elements were not considered in the analysis. Numerical variables were reported as means and standard deviation, while categorical variables were reported as proportions and percentages. The Chi square test was used to test the correlation between different categorical variables.

\section{Results}

3.1. Basic Data of Enrolled Students. A total of 420 students participated in the study representing six years of enrollment, 70 students for each one with 202 males and 218 females. Our questionnaire had a response rate of $86 \%$. About $65.7 \%$ of students (276 out of 420) went to public schools, while students who went to private ( 85 out of 420 ) and international schools (59 out of 420 ) represented $20.2 \%$ and $14.1 \%$ of our sample, respectively.

3.2. Attitudes of Students towards Clinical Research. A total of $74.2 \%$ (312 out of 420 ) agreed that "clinical research methodology should be a mandatory knowledge requirement for all physicians." About $80 \%$ of students (336 out of 420 ) agreed that "all medical advances are based on the proper application of the scientific methodology." Generally, 53.2\% of enrolled students (224 out of 420) disagreed with the statement that "following the scientific research methodology adds difficulty to clinical research practice." A summary of the findings of the attitudes section is presented in Table 1.

A total of $86 \%$ (361 out of 420) of enrolled students agreed that undergraduates should participate in clinical research. However, only $23.8 \%$ (100 out of 420) among all enrolled students reported engagement in clinical research activities. Among the sampled students, $60.7 \%$ (255 out of 420 ) expressed willingness to conduct clinical research in the future.

Subgroup analysis showed that males and females did not show a significant difference in their average attitudes towards clinical research ( $p$ value $=0.07$ ). Students in different enrollment years showed different levels of positive attitudes with the 5th and 6th years reporting the highest positive attitudes ( $p$ value $<0.05$ in 6 of 8 questions). Students from different high school backgrounds showed no significant difference in their attitude towards clinical research ( $p$ value $=0.1)$. Students in different enrollment years reported variable degrees of engagement in clinical research activities with the 4 th year achieving the highest level of research participation as illustrated in Figure 1.

Gender difference had no impact on students' research participation or willingness to conduct research in the future. Moreover, students from different high school backgrounds showed no difference in the extent of research participation, but students who studied in international schools expressed more willingness to conduct clinical research in the future, compared to students from public or private schools ( $p$ value $=0.046$ ).

3.3. Knowledge about Clinical Research. Students showed low knowledge scores averaging from $1.2 \pm 0.4$ for the 2nd year to $2.6 \pm 0.2$ for the 4 th year ( $20 \%$ to $43.3 \%$ ) on a scale of six questions. Only $42.3 \%$ (128 out of 420 ) could correctly define 
TABLE 1: The attitudes of medical students towards clinical research methodology and practice.

\begin{tabular}{|c|c|c|c|}
\hline Items: & Agree & Undecided & Disagree \\
\hline $\begin{array}{l}\text { (1) Managing clinical problems can be easier if the } \\
\text { scientific approach is properly followed. }\end{array}$ & $\begin{array}{c}364 \\
(86.6 \%)\end{array}$ & $\begin{array}{c}43 \\
(10.3 \%)\end{array}$ & $\begin{array}{c}13 \\
(3.1 \%)\end{array}$ \\
\hline $\begin{array}{l}\text { (2) Clinical research skills can significantly improve the } \\
\text { physician's clinical practice. }\end{array}$ & $\begin{array}{c}366 \\
(87.1 \%)\end{array}$ & $\begin{array}{c}36 \\
(8.5 \%)\end{array}$ & $\begin{array}{c}18 \\
(4.4 \%)\end{array}$ \\
\hline $\begin{array}{l}\text { (3) All medical advances are based on the proper } \\
\text { application of the scientific methodology. }\end{array}$ & $\begin{array}{c}336 \\
(80.1 \%)\end{array}$ & $\begin{array}{c}53 \\
(12.6 \%)\end{array}$ & $\begin{array}{c}31 \\
(7.3 \%)\end{array}$ \\
\hline $\begin{array}{l}\text { (4) Clinical research methodology should be a } \\
\text { mandatory knowledge requirement for all physicians. }\end{array}$ & $\begin{array}{c}312 \\
(74.2 \%)\end{array}$ & $\begin{array}{c}43 \\
(10.2 \%)\end{array}$ & $\begin{array}{c}65 \\
(15.6 \%)\end{array}$ \\
\hline $\begin{array}{l}\text { (5) Being oriented with the clinical research } \\
\text { methodology is necessary to obtain accurate clinical } \\
\text { data. }\end{array}$ & $\begin{array}{c}339 \\
(80.7 \%)\end{array}$ & $\begin{array}{c}18 \\
(4.2 \%)\end{array}$ & $\begin{array}{c}63 \\
(15.1 \%)\end{array}$ \\
\hline $\begin{array}{l}\text { (6) Limiting medical practice to scientific findings only } \\
\text { makes the practicing physicians narrow-minded. }\end{array}$ & $\begin{array}{c}124 \\
(29.5 \%)\end{array}$ & $\begin{array}{c}71 \\
(16.8 \%)\end{array}$ & $\begin{array}{c}225 \\
(53.7 \%)\end{array}$ \\
\hline $\begin{array}{l}\text { (7) Following the scientific research methodology adds } \\
\text { difficulty to clinical research practice. }\end{array}$ & $\begin{array}{c}127 \\
(30.2 \%)\end{array}$ & $\begin{array}{c}69 \\
(16.5 \%)\end{array}$ & $\begin{array}{c}224 \\
(53.3 \%)\end{array}$ \\
\hline $\begin{array}{l}\text { (8) Undergraduate students should participate in } \\
\text { clinical research projects. }\end{array}$ & $\begin{array}{c}361 \\
(86 \%)\end{array}$ & $\begin{array}{c}28 \\
(6.4 \%)\end{array}$ & $\begin{array}{c}31 \\
(7.4 \%)\end{array}$ \\
\hline
\end{tabular}

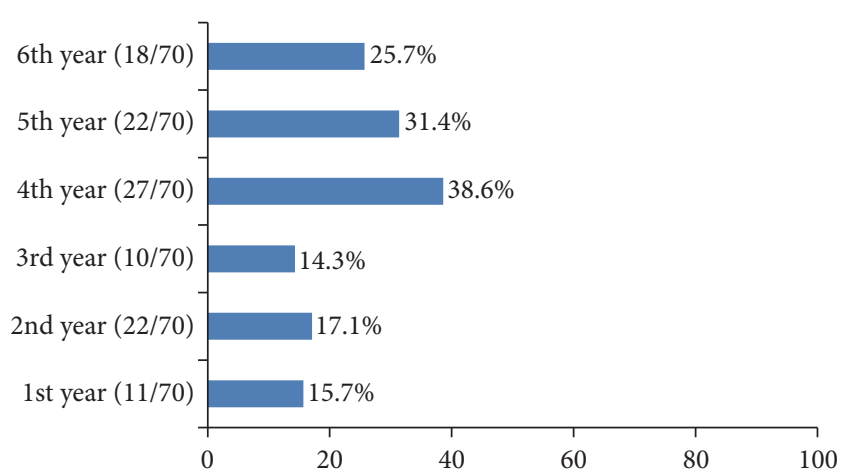

FIGURE 1: Percentage of students' participation in clinical research activities among different years of enrollment.

the concept of clinical research and only $18.6 \%$ (78 out of 420 ) could differentiate the necessary parts of scientific papers. These data are hypothesis-generating and future studies with detailed assessment of students' clinical research knowledge are recommended.

Different academic years showed different average scores with the 4th-year students achieving the highest scores among the sampled students, as illustrated in Figure 2. Difference in gender and high school background did not have an impact on the students' research knowledge.

\subsection{Perceived Barriers against Participation in Clinical Re-} search. Students highlighted seven barriers as lack of time (320 out of 420), lack of proper mentoring (306 out of 420), lack of necessary knowledge (271 out of 460), loss of interest (221 out of 420), and deficient funding (282 out of 420) and database accessibility (174 out of 420).

Females expressed more importance for six barriers than males with particular statistical significance for lack of mentoring $(p$ value $=0.015)$ and lack for research facilities ( $p$ value $=0.02)$, as illustrated by Figure 3. Only lack of time

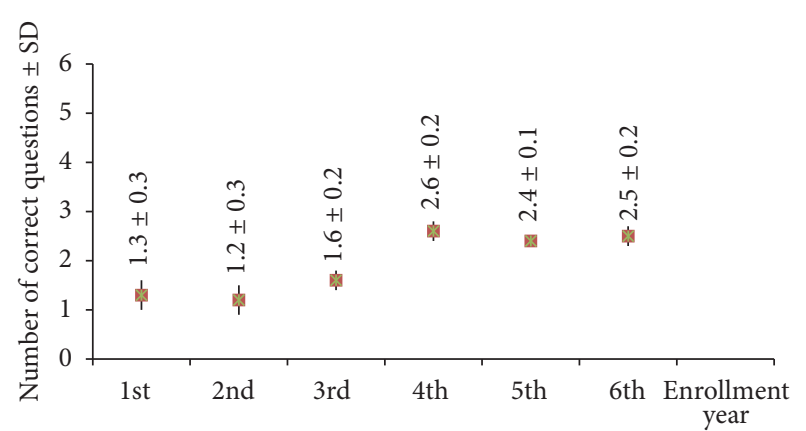

FIGURE 2: The mean knowledge scores \pm standard deviation for each year of enrollment in medical school.

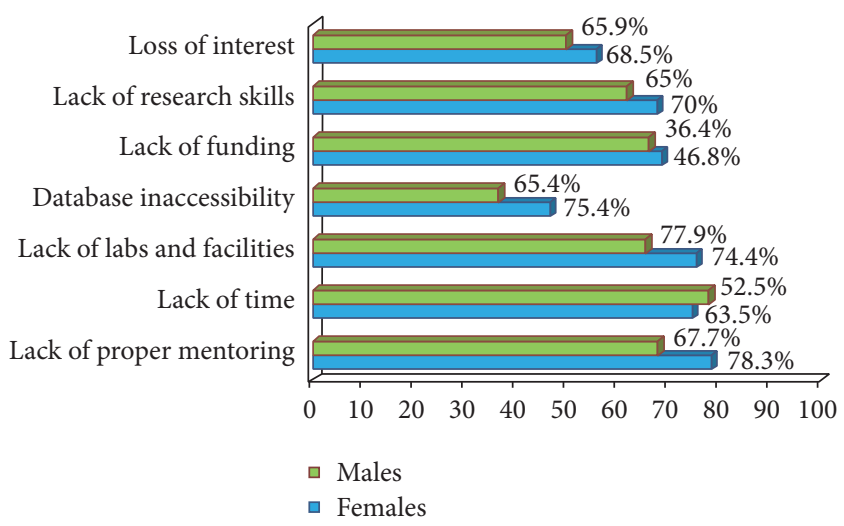

FIGURE 3: Gender difference regarding significance of barriers against participation in research activities.

was assigned as a more important barrier by males; however that was not statistically significant $(p$ value $=0.07$ ). Different years of enrollment implied variable importance for each barrier; for example, lack of time was reported highest among 
3rd-year students (88.6\%), while loss of interest was reported highest by 2 nd-year students (64.3\%).

\section{Discussion}

Our study showed high positive attitudes among Egyptian medical students towards clinical research; however, it was associated with relatively low knowledge scores. Although $86 \%$ of students agreed that undergraduates should participate in clinical research, only $23.8 \%$ of them reported engagement in research activities. Students highlighted several barriers as lack of mentoring, funding, time, facilities, database inaccessibility, or poor research knowledge and interest. Our results are consistent with the results of several studies that found a gap between the students' positive attitudes towards scientific research and their actual engagement in research activities $[12,19,20]$.

Also, it shows poor perception of clinical research concepts especially regarding statistical concepts and scientific writing. This is comparable to the results by Khan and his colleagues where students achieved a mean knowledge score of $49 \%$ on a percentage scale [12]. Maximal knowledge scores were achieved by students in the 4 th grade where a dense clinical research course is taken, indicating a significant contribution of the academic curriculum to fostering research knowledge among medical students.

In our study, gender difference did not have a significant effect on students' knowledge, attitudes, or participation in research activities. A recent systematic review of the literature by Amgad and colleagues found that gender difference did not impact any of these parameters; however males had a higher probability of publishing their medical school projects than females [5].

Our study concluded that students from different academic years showed variable results on the attitudes and knowledge scales where the students of the 4th year achieved the highest knowledge scores and percentage of research participation. This is comparable to the results of other longitudinal studies that showed improving knowledge and attitudes towards scientific research as students upgrade during the medical school [11, 21, 22].

Unlike a former study by Amin and colleagues that showed significantly more positive attitudes among students of private/international schools [19], our study did not conclude a significant impact of high school background on the students' knowledge or participation in clinical research. However, students of international schools expressed more willingness to conduct clinical research in the future than their peers from public or private schools.

In this study, $41.1 \%$ of the participants reported difficulty accessing the relevant electronic databases; however, we believe this barrier is more evident in developing than developed countries as indicated by Williams and colleagues [23]. Although students in developing countries, including Egypt, show high interests in clinical research $[5,24]$, they have an access to a lower number of research educational programs than their peers in developed ones [25].

Several studies in different countries reported lack of time as a major barrier against engagement in clinical research
[11, 12, 26]. Mandating research training and participation in medical schools can enhance the scientific productivity of medical students after graduation [27]. One study in Germany by Cursiefen and Altunbas found that student publications represented $28 \%$ of the research outcome of one institution [28].

Echoing other similar reports [11, 12], lack of mentoring and difficulty to attain a research supervisor were reported as a significant barrier by $72.8 \%$ of sampled students in our study. Other studies have reported financial difficulty and lack of research training as major drawbacks against research involvement $[25,27]$.

To the best of our knowledge, this is the first study to assess the attitudes towards clinical research, in particular, among medical students. We believe our results are generalizable to most Egyptian medical students, because most medical schools in Egypt follow the same educational system. Also longitudinal comparison between different academic grades provided some insights and recommendations to enhance students' participation in clinical research.

4.1. Study Limitations and Future Research Implications. Our questionnaire did not target full assessment of the students' knowledge; therefore, future studies are encouraged to address this variable in a detailed manner. Although we exclusively used closed-ended questions, we recommend future studies to use open-ended questions to further explore the students' beliefs regarding the subject. We only assessed the encountered barriers; however, examination of the motives which would encourage students to take part in clinical research can be of benefit. The percentages of enrolled medical students from private and international schools were low, compared to public schools. Also it would be valuable to assess the students' attitudes towards other research types as basic science research and translational and community based research. Studies like ours should be conducted on a regular basis because they provide an assessment tool for all efforts, exerted to increase student participation in clinical research.

4.2. Implications for Medical Education. Based on the findings of the present study, we suggest several recommendations that need to be considered by policy makers. Our study showed highest knowledge levels about clinical research among the fourth-year medical students, most probably due to the dense clinical research course that students take during that year; therefore, we highly recommend mobilizing that course to early preclinical years to provide students with an earlier exposure to clinical research. Also, students in the 5th and 6th enrollment years showed retention of clinical research information after the 4th year's course, highlighting the benefit of this course and the value of sustaining research exposure during later years of medical schools. Lack of time was pointed out as a significant barrier against research education and performance; therefore, voluntary activities such as research participation tend to be marginalized. Thus, we recommend mandating research participation as an essential requirement for graduation. Also, the density of medical education curricula should be reviewed on a global scale. 


\section{Conclusion}

Although the majority of students showed positive attitudes towards clinical research, they reported low participation in research activities associated with low knowledge scores. A number of barriers need to be addressed in order to enhance students' participation in clinical research such as lack of mentoring, funding, and poor availability of research facilities and access to scientific databases.

\section{Additional Points}

Data Confidentiality and Consent to Participate. Data were collected using a validated, anonymous self-administrated questionnaire after explaining the voluntary nature of the questionnaire and obtaining a verbal consent from the study participants. The confidentiality of obtained data was maintained according to the Helsinki Declaration of bioethics.

\section{Disclosure}

This study was not funded by an external source other than the Faculty of Medicine, Ain Shams University.

\section{Competing Interests}

All authors declare they have no competing interests.

\section{Authors' Contributions}

Abdelrahman Ibrahim Abushouk designed the study and contributed in data collection and analysis and drafting the manuscript. Abdelrahman Nazmy Hatata contributed in data analysis and drafting the manuscript. Ibrahim Mahmoud Omran contributed in data collection and drafting the manuscript. Mohammed Mahmoud Youniss contributed in data collection and analysis. Khaled Fayez Elmansy contributed in data collection and analysis. Abdullah Gad Meawad contributed in data collection and analysis.

\section{Acknowledgments}

The authors would like to acknowledge the staff members at Public Health Department, Faculty of Medicine, Ain Shams University for their great help and support in conducting this study.

\section{References}

[1] L. E. Rosenberg, "Physician-scientists-endangered and essential," Science, vol. 283, no. 5400, pp. 331-332, 1999.

[2] T. R. Zemlo, H. H. Garrison, N. C. Partridge, and T. J. Ley, "The physician-scientist: career issues and challenges at the year 2000," The FASEB Journal, vol. 14, no. 2, pp. 221-230, 2000.

[3] J. B. Wyngaarden, "The clinical investigator as an endangered species," Bulletin of the New York Academy of Medicine, vol. 57, no. 6 , pp. 415-426, 1981.

[4] S. S. Solomon, S. C. Tom, J. Pichert, D. Wasserman, and A. C. Powers, "Impact of medical student research in the development of physician-scientists," Journal of Investigative Medicine, vol. 51, no. 3, pp. 149-156, 2003.
[5] M. Amgad, M. M. K. Tsui, S. J. Liptrott, and E. Shash, "Medical student research: an integrated mixed-methods systematic review and meta-analysis," PLoS ONE, vol. 10, no. 6, Article ID e0127470, 2015.

[6] S. Segal, T. Lloyd, P. S. Houts, P. L. Stillman, R. L. Jungas, and R. B. Greer III, “The association between students' research involvement in medical school and their postgraduate medical activities," Academic Medicine, vol. 65, no. 8, pp. 530-533, 1990.

[7] J. J. Reinders, T. J. B. Kropmans, and J. Cohen-Schotanus, "Extracurricular research experience of medical students and their scientific output after graduation," Medical Education, vol. 39, no. 2, p. 237, 2005.

[8] R. L. Houlden, J. B. Raja, C. P. Collier, A. F. Clark, and J. M. Waugh, "Medical students' perceptions of an undergraduate research elective," Medical Teacher, vol. 26, no. 7, pp. 659-661, 2004.

[9] W. H. Frishman, "Student research projects and theses: should they be a requirement for medical school graduation?" Heart Disease, vol. 3, no. 3, pp. 140-144, 2001.

[10] A. I. Abushouk, "Evolution of Fagan's nomogram; a commentary," EMERGENCY, vol. 4, pp. 114-115, 2016.

[11] S. E. Straus, C. Straus, and K. Tzanetos, "Career choice in academic medicine: systematic review," Journal of General Internal Medicine, vol. 21, no. 12, pp. 1222-1229, 2006.

[12] H. Khan, M. R. H. Khawaja, A. Waheed, M. A. Rauf, and Z. Fatmi, "Knowledge and attitudes about health research amongst a group of Pakistani medical students," BMC Medical Education, vol. 6, article 54, 2006.

[13] D. R. Siemens, S. Punnen, J. Wong, and N. Kanji, "A survey on the attitudes towards research in medical school," BMC Medical Education, vol. 10, article 4, 2010.

[14] F. L. Brancati, L. A. Mead, D. M. Levine, D. Martin, S. Margolis, and M. J. Klag, "Early predictors of career achievement in academic medicine," The Journal of the American Medical Association, vol. 267, no. 10, pp. 1372-1376, 1992.

[15] C. Galletly, A. Chur-Hansen, T. Air, and I. Chapman, "Academics of the future? A survey of final year medical students," Australasian Psychiatry, vol. 17, no. 6, pp. 502-505, 2009.

[16] H. H. N. Kumar, S. Jayaram, G. Kumar et al., "Perception, practices towards research and predictors of research career among UG medical students from coastal South India: a crosssectional study," Indian Journal of Community Medicine, vol. 34, no. 4, pp. 306-309, 2009.

[17] E. B. Puertas, C. Arósquipa, and D. Gutiérrez, "Factors that influence a career choice in primary care among medical students from high-, middle-, and low-income countries: a systematic review," Revista Panamericana de Salud Pública, vol. 34, pp. 351-358, 2013.

[18] E. Von Elm, D. G. Altman, M. Egger, S. J. Pocock, P. C. Gøtzsche, and J. P. Vandenbroucke, "The Strengthening the Reporting of Observational Studies in Epidemiology (STROBE) statement: guidelines for reporting observational studies," Preventive Medicine, vol. 45, no. 4, pp. 247-251, 2007.

[19] T. T. Amin, F. Kaliyadan, E. A. Al Qattan, M. H. Al Majed, H. S. Al Khanjaf, and M. Mirza, "Knowledge, attitudes and barriers related to participation of medical students in research in three Arab Universities," Education in Medicine Journal, vol. 4, no. 1, 2012.

[20] I. Vodopivec, A. Vujaklija, M. Hrabak, I. K. Lukić, A. Marušić, and M. Marušić, "Knowledge about and attitude towards science of first year medical students," Croatian Medical Journal, vol. 43, no. 1, pp. 58-62, 2002. 
[21] A. Anastasi, Psychological Testing, Macmillan, New York, NY, USA, 6th edition, 1998.

[22] L. B. Mokkink, C. B. Terwee, D. L. Patrick et al., "The COSMIN checklist for assessing the methodological quality of studies on measurement properties of health status measurement instruments: an international Delphi study," Quality of Life Research, vol. 19, no. 4, pp. 539-549, 2010.

[23] C. D. Williams, E. L. Pitchforth, and C. O’Callaghan, "Computers, the Internet and medical education in Africa," Medical Education, vol. 44, no. 5, pp. 485-488, 2010.

[24] N. A. De Oliveira, M. R. Luz, R. M. Saraiva, and L. A. Alves, "Student views of research training programmes in medical schools," Medical Education, vol. 45, no. 7, pp. 748-755, 2011.

[25] T. D. N. Silva, L. C. da Cunha Aguiar, J. Leta et al., "Role of the undergraduate student research assistant in the new millennium," Cell Biology Education, vol. 3, no. 4, pp. 235-240, 2004.

[26] K. M. AlGhamdi, N. A. Moussa, D. S. AlEssa, N. AlOthimeen, and A. S. Al-Saud, "Perceptions, attitudes and practices toward research among senior medical students," Saudi Pharmaceutical Journal, vol. 22, no. 2, pp. 113-117, 2014.

[27] S. J. K. Park, M. M. S. Liang, T. Sherwin, and C. N. J. McGhee, "Completing an intercalated research degree during medical undergraduate training: barriers, benefits and postgraduate career profiles," The New Zealand Medical Journal, vol. 123, no. 1323, pp. 24-33, 2010.

[28] C. Cursiefen and A. Altunbas, "Contribution of medical student research to the Medline ${ }^{\mathrm{TM}}$-indexed publications of a German medical faculty," Medical Education, vol. 32, no. 4, pp. 439-440, 1998. 


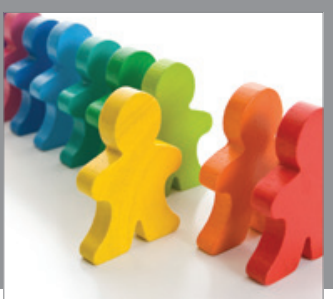

Autism

Research and Treatment
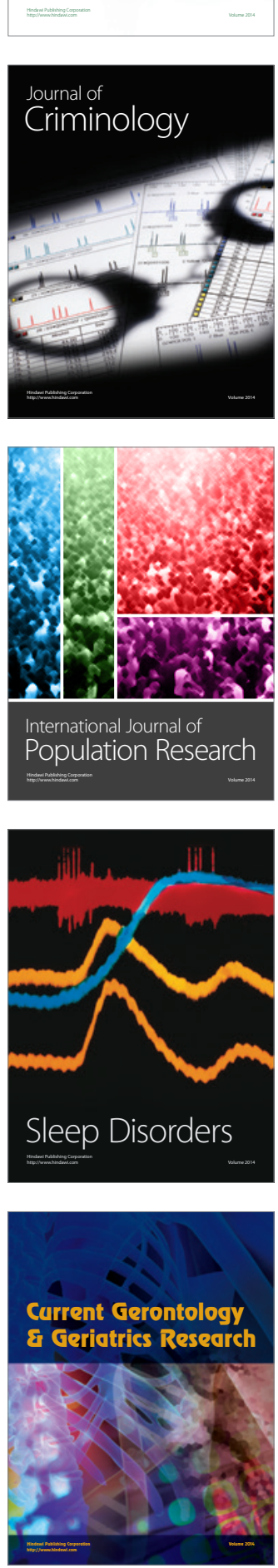

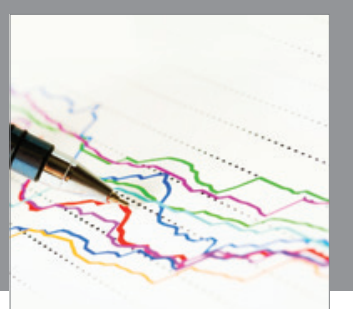

Economics

Research International
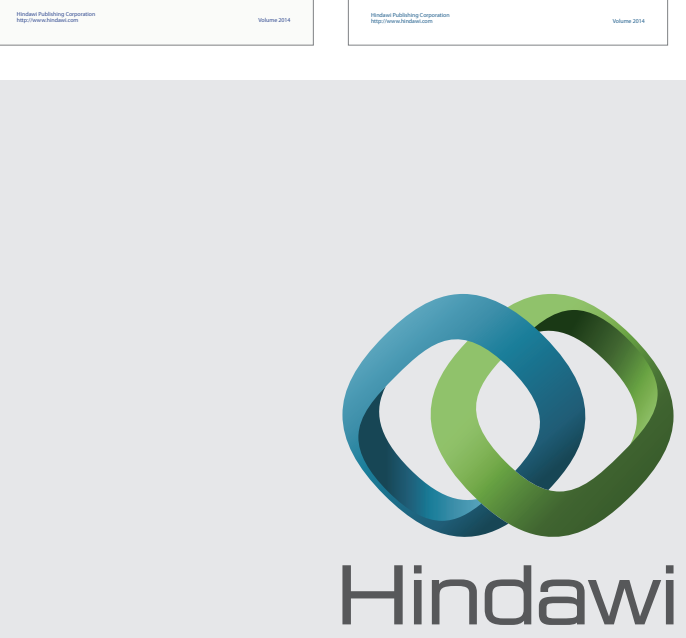

Submit your manuscripts at

http://www.hindawi.com
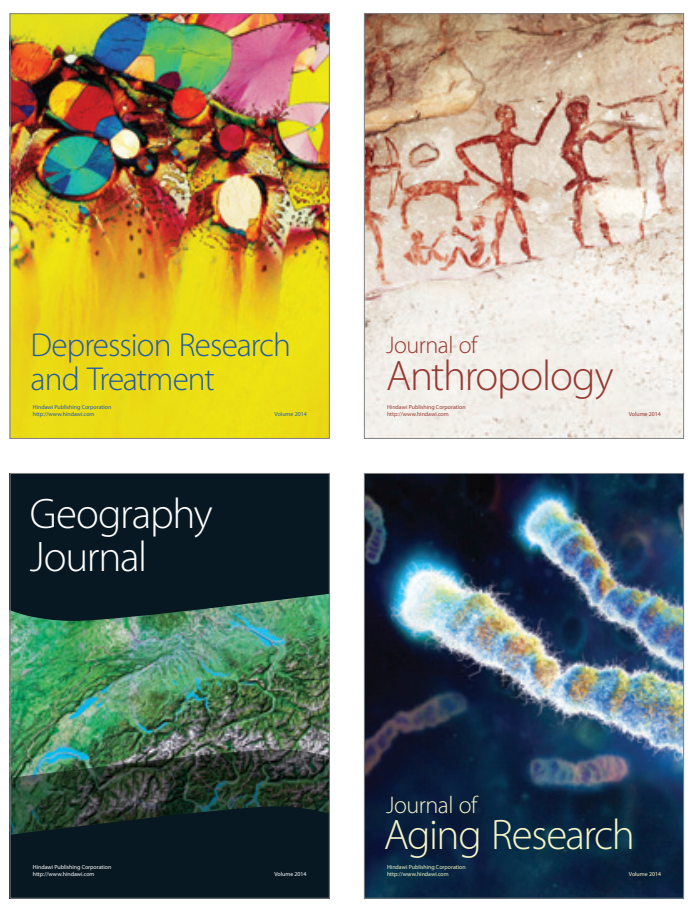
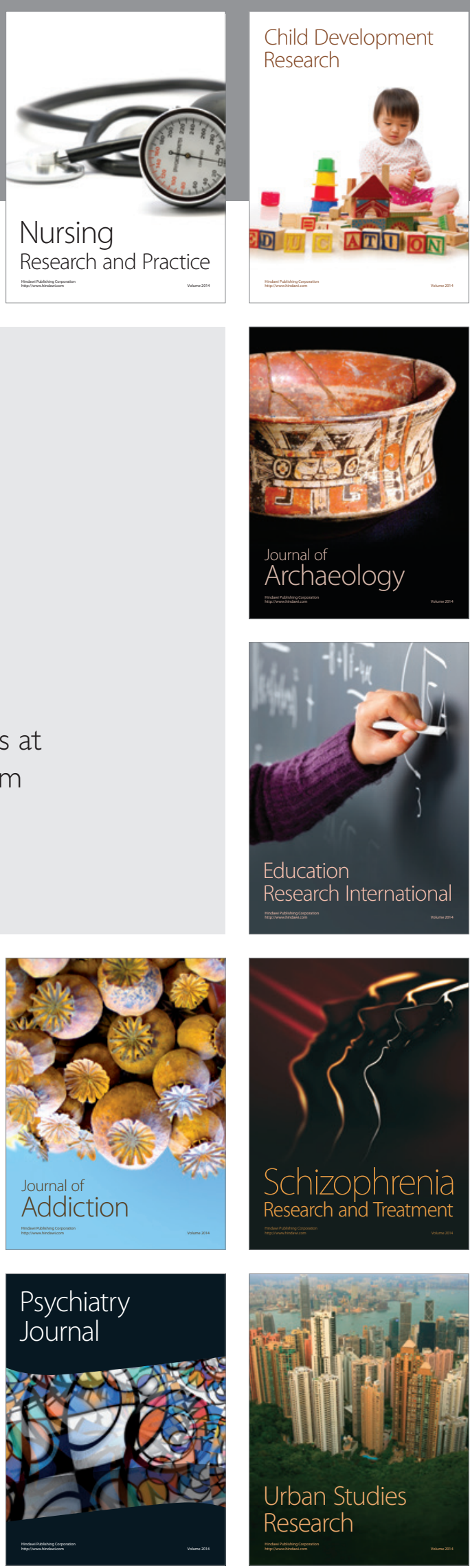